\title{
Impact of Erythrocyte Duffy Antigen Genetic Polymorphism on the Distribution of Gro $\beta-T$, a Novel Human CXC Chemokine
}

\author{
Timothy W Hepburn ${ }^{1}$, LeeAnn P Tobia ${ }^{1}$, Wei Shi ${ }^{1}$ \\ Timothy A Mclntyre ${ }^{2}$ and Charles B Davis ${ }^{2}$
}

${ }^{1}$ Drug Metabolism and Pharmacokinetics, GlaxoSmithKline, King of Prussia, Pennsylvania

${ }^{2}$ Drug Metabolism and Pharmacokinetics, GlaxoSmithKline, Collegeville, Pennsylvania

Received, August 26, 2007; Revised, October 2, 2007; Accepted, October 9, 2007; Published October 10, 2007.

ABSTRACT - Purpose. Gro $\beta$-T, a human CXC chemokine, has been studied for its potential to mobilize stem cells. Chemokines bind specifically to receptors on target immune cells but also to a homologous erythrocyte blood group antigen, the Duffy Antigen/Receptor for Chemokines (DARC) that is subject to genetic polymorphism in humans. A mutation in the DARC gene is common among African Americans and results in lack of expression of the erythrocyte antigen. We used a combination of in vitro studies of Groß-DARC interaction and pharmacokinetic simulation to anticipate the potential impact of this polymorphism on the pharmacokinetics of Gro $\beta$-T. Methods. $\left[{ }^{125} \mathrm{I}\right] \mathrm{Gro} \beta$ $\mathrm{T}$ was incubated in Caucasian blood to characterize the concentration dependence of the blood to plasma concentration ratio (B/P). Affinity and capacity of binding was estimated by Scatchard analysis; specificity was investigated by competitive displacement with a CC chemokine. The $\mathrm{B} / \mathrm{P}$ value $(7 \mathrm{nM})$ was then determined in blood from 8 African American subjects. Duffy antigen expression was determined by antibody agglutination. A pharmacokinetic model was developed which accounted for blood-cell binding. Simulations were performed to explore effects of dose regimen and DARC expression on the Gro $\beta$-T plasma concentration-time profile. Results. Gro $\beta-T$ affinity and capacity for DARC (Caucasian blood) were $23.0 \pm 1.2$ and $37.7 \pm 0.6 \mathrm{nM}$, respectively; excess CC chemokine fully displaced $\left[{ }^{125} \mathrm{I}\right] \mathrm{Gro} \beta-\mathrm{T}$. Chemokine binding was highly correlated with the presence or absence of the Duffy antigen $(p<0.01)$ in African American blood; the proportion of subjects for which binding was observed (3/8), was consistent with the reported frequency of DARC expression in this population. Counter to intuition, in the terminal disposition phase at low doses, concentrations of free Gro $\beta-T$ in the presence of
DARC may be substantially higher than in the absence of DARC. Conclusion. Dissociation from the erythrocyte antigen may lead to greater persistence, at low doses, of free Gro $\beta$-T in the blood of individuals expressing the chemokine sink.

\section{INTRODUCTION}

Chemokines are potent chemotactic cytokines classified structurally by the invariant position of cysteine residues near the amino terminus of the protein. Chemokines attract host defense effector cells along concentration gradients and are involved in numerous physiological processes, including leukocyte trafficking, inflammation, angiogenesis, tumor growth, and human immunodeficiency virus suppression (1-3). The CXC chemokine family is involved in chemotaxis and activation of neutrophils.

Gro $\beta-T$ is a novel truncated form of the human CXC chemokine growth-related gene product beta. Gro $\beta$-T interacts specifically with the CXCR2 receptor. A single dose of Gro $\beta$-T results in rapid mobilization of long-term repopulating hematopoietic stem cells and multilineage as well as lineage restricted progenitor cells. In a murine peripheral blood transplantation model, stem cells mobilized by Gro $\beta$-T alone or in combination with G-CSF demonstrated enhanced neutrophil and platelet engraftment compared to stem cell mobilization by G-CSF alone. Gro $\beta$-T has also demonstrated potential to mobilize hematopoietic cells in the rhesus monkey $(4,5)$.

Corresponding Author: Charles B Davis, PhD.GlaxoSmithKline Drug Discovery Drug Metabolism and Pharmacokinetics, 1250 S Collegeville Rd, Collegeville, PA; E-mail: Charles.B.Davis@gsk.com 
In the present study, we have characterized the interaction of Gro $\beta$-T with DARC using whole human blood from Caucasian and African American volunteers. DARC is a promiscuous erythrocyte receptor, with significant homology to chemokine receptors, that binds CC and CXC ligands $(6,7)$.

As DARC is not involved in signalling, it has been proposed that it acts as a sink to limit the concentration and action of circulating chemokines (8). A mutation in the DARC gene is common among African Americans and results in lack of expression of the erythrocyte antigen. This mutation protects this population from infection by the malaria parasite, $P$. vivax, which uses DARC to enter susceptible red cells (9). The potential impact of the these differences in DARC expression on the pharmacokinetics of Gro $\beta$ - $T$ in humans have been studied using mathematical modeling and simulation.

\section{METHODS}

\section{Chemicals.}

Recombinant Gro $\beta$-T and RANTES were expressed in E coli at GlaxoSmithKline R\&D (King of Prussia PA) and purified to homogeneity. $\left[{ }^{125} \mathrm{I}\right] \mathrm{Gro} \beta$-T was prepared as described previously (10). Specific radioactivity was $\sim 0.04 \mathrm{Ci} / \mathrm{g}$. Greater than $98 \%$ of the radioactivity in the preparation was associated with the protein by diafiltration and radiochemical purity exceeded $90 \%$ by SDS-PAGE.

\section{Blood Partitioning.}

All plasma and blood measurements were performed with calibrated positive displacement pipettes. Three healthy Caucasian volunteers provided whole blood on the morning of each study day in Vacutainer ${ }^{\circledR}$ tubes containing EDTA as anticoagulant. Promptly after collection, blood was placed on wet ice. $\left[{ }^{125} \mathrm{I}\right] \mathrm{Gro} \beta$ - $\mathrm{T}$ was added to the ice-cold blood at nominal concentrations of 50 $\mathrm{ng} / \mathrm{mL}(7 \mathrm{nM})$ and $25 \mu \mathrm{g} / \mathrm{mL}(3300 \mathrm{nM})$. Aliquots were removed for radio-analysis and the remaining blood was placed in a shaking water bath at approximately $37^{\circ} \mathrm{C}$ for 10 or $60 \mathrm{~min}$. Following incubation, plasma was separated by centrifugation, and blood cells were washed sequentially (three times) with $10 \mathrm{mM}$ sodium phosphate, $150 \mathrm{mM}$ sodium chloride, $\mathrm{pH} 7.4$ buffer (PBS) to remove loosely associated radioactivity.
Radioactivity in blood, plasma, PBS washes, and blood cells was determined by scintillation counting. For comparison, ice-cold blood containing $\left[{ }^{125} \mathrm{I}\right] \mathrm{Gro} \beta$-T was processed and analyzed in the same manner as the 10 and $60 \mathrm{~min}$ $37^{\circ} \mathrm{C}$ incubations (identified in Table 1 as the zero time point incubation). The blood to plasma concentration ratio was calculated as was the percentage of radioactivity in plasma, the PBS washes and the residual cell pellet. Mean recovery of radioactivity exceeded $91 \%$.

The effect of RANTES $(25 \mu \mathrm{g} / \mathrm{mL}, 2500$ $\mathrm{nM})$, a CC chemokine, on the blood cell association of $\left[{ }^{125} \mathrm{I}\right] \mathrm{Gro} \beta-\mathrm{T}(50 \mathrm{ng} / \mathrm{mL}, 7 \mathrm{nM}$, on wet ice) was studied similarly. Also, to confirm stability of the radiolabel in the whole blood incubations, for selected samples, the percentage of trichloroacetic acid soluble radioactivity in plasma was determined as described previously (11).

To explore the relationship between Duffy antigen phenotype and Gro $\beta$-T blood to plasma concentration ratio in African American blood, eight healthy African American volunteers provided whole blood and $\left[{ }^{125} \mathrm{I}\right] \mathrm{Gro} \beta$-T was added, on ice (50 $\mathrm{ng} / \mathrm{mL}, 7 \mathrm{nM}$ ). Aliquots were removed for radioanalysis and the remaining blood was centrifuged to collect plasma. Radioactivity in blood and plasma was determined and the blood to plasma concentration ratio calculated. Duffy antigen phenotyping was determined by the agglutination of erythrocytes after incubation of the cells with antiFya and anti-Fyb antibodies (Mainline Clinical Laboratories Transfusion Services, Lankenau campus, Wynnewood, PA).

\section{Displacement of cell-bound $\left[{ }^{125} \mathrm{I}\right] \mathrm{Gro} \beta-\mathrm{T}$.}

To determine whether cell-bound radioactivity was associated with the cell surface or internalized, displacement studies were performed with excess unlabeled Gro $\beta$-T. Briefly, Caucasian blood from 3 donors was incubated on ice, or for $1 \mathrm{~h}$ at $37^{\circ} \mathrm{C}$, with $7 \mathrm{nM}\left[{ }^{125} \mathrm{I}\right] \mathrm{Gro} \beta$-T. Ice-cold incubation was expected to inhibit internalization but not binding, whereas at $37{ }^{\circ} \mathrm{C}$, the potential exists for both binding and internalization (8). Cell pellets were washed three time with PBS (as in the blood partitioning experiments) then incubated with 3300 $\mathrm{nM}$ unlabeled Gro $\beta$-T, in PBS, at $4{ }^{\circ} \mathrm{C}$ overnight. Following centrifugation, radioactivity in the supernatant and pellet was determined. Cellassociated radioactivity, soluble radioactivity and 
recovery are reported as percentage radioactivity in the initial blood pellet (Table 2).

\section{Binding isotherm.}

Ice-cold EDTA blood from a single Caucasian donor was spiked, in triplicate, with $\left[{ }^{125} \mathrm{I}\right] \mathrm{Gro} \beta-\mathrm{T}$ at concentrations ranging from 1 to $1000 \mathrm{nM}$. An aliquot of each blood incubation was removed for radio-analysis and the remaining blood was centrifuged to collect plasma. Blood to plasma radioactivity ratios were calculated from equal volumes of blood and plasma using calibrated positive displacement pipettes. Plasma concentrations were obtained by dividing the total blood concentration by the $\mathrm{B} / \mathrm{P}$ radioactivity ratio. Blood concentrations of free and cell-bound Gro $\beta-\mathrm{T}$ $\left([\mathrm{Gro} \beta-\mathrm{T}]_{\mathrm{F}}\right.$ and $[\mathrm{Gro} \beta-\mathrm{T}]_{\mathrm{B}}$, respectively) were calculated from total blood concentrations ([Gro $\beta$ $\mathrm{T}]_{\mathrm{T}}$ ), plasma concentrations $\left([\mathrm{Gro} \beta-\mathrm{T}]_{\mathrm{P}}\right)$ and blood hematocrit $(\mathrm{H})$ using the following equations:

$$
\begin{aligned}
& {[\mathrm{Gro} \beta-\mathrm{T}]_{\mathrm{F}}=[\mathrm{Gro} \beta-\mathrm{T}]_{\mathrm{P}} \times(1-\mathrm{H})} \\
& {[\mathrm{Gro} \beta-\mathrm{T}]_{\mathrm{B}}=[\mathrm{Gro} \beta-\mathrm{T}]_{\mathrm{T}}-[\mathrm{Gro} \beta-\mathrm{T}]_{\mathrm{F}}}
\end{aligned}
$$

Blood hematocrit was determined using standard techniques. A single-site binding equation was fitted to the $[\mathrm{Gro} \beta-\mathrm{T}]_{\mathrm{B}}$ vs. [Gro $\left.\beta-\mathrm{T}\right]_{\mathrm{F}}$ data using Grafit (Version 4.06) to estimate the apparent dissociation constant $\left(\mathrm{K}_{\mathrm{D}}\right)$, binding capacity $\left(\mathrm{R}_{\text {TOTAL }}\right)$ and the associated standard error of the parameter estimates.

Table 1. Distribution of $\left[{ }^{125} \mathrm{I}\right]$ Gro in Human Caucasian Blood in vitro ${ }^{a}$

\begin{tabular}{ccccc} 
Conc (nM) & Time (min) & B/P Ratio & \% Plasma & \% Cells \\
\hline 7 & 0 & $1.837(0.089)$ & $26.63(2.48)$ & $49.63(7.27)$ \\
& 60 & $1.663(0.200)$ & $24.45(3.42)$ & $33.50(8.98)$ \\
3300 & 0 & $0.573(0.068)$ & $76.37(18.50)$ & $1.92(0.29)$ \\
& 60 & $0.631(0.062)$ & $74.74(1.61)$ & $1.60(0.28)$ \\
Gro, & 0 & $0.722(0.055)$ & $77.47(7.55)$ & $2.18(0.21)$ \\
RANTES $^{b}$ & 0 &
\end{tabular}

${ }^{a}$ Data are expressed as mean (standard deviation), $\mathrm{n}=3$.

${ }^{b}$ Gro and RANTES concentrations were 7 and $2500 \mathrm{nM}$, respectively.

Table 2. Displacement of [ $\left.{ }^{125} \mathrm{I}\right]$ Gro from Human Caucasian Blood Cells in vitro

\begin{tabular}{ccccc} 
Subject & Condition & $\begin{array}{c}\text { \% Cell } \\
\text { Assoc }\end{array}$ & \% Displaced & \% Recovery \\
\hline 1 & ice-cold & 22.6 & 78.9 & 103 \\
& 1 h, $37^{\circ} \mathrm{C}$ & 32.2 & 70.0 & 102 \\
2 & ice-cold & 22.6 & 73.6 & 96.2 \\
3 & ice-cold & 22.6 & 73.3 & 95.9 \\
Mean (SD) & ice-cold & $22.6(0.0)$ & $75.3(3.2)$ & $98.4(4.0)$ \\
\hline
\end{tabular}




\section{Human Pharmacokinetic Simulation.}

The potential impact of differential DARC expression on the intravenous pharmacokinetics of Gro $\beta-T$ was estimated using Trial Simulator (Pharsight Corp., Version 2.1.2, Mountain View, CA). A 2-compartment model with first-order elimination from the central compartment was employed. Consistent with rodent pharmacokinetic studies of Gro $\beta$-T (10) and the cytokine literature (12), the central compartment volume was fixed to blood volume, the volume of distribution at steadystate was fixed to extracellular water and the total clearance was fixed to the glomerular filtration rate (13). Human body weight of $70 \mathrm{~kg}$ was assumed. In the presence of DARC, additional terms were included for reversible binding (14), and the affinity $\left(\mathrm{K}_{\mathrm{D}}\right)$ and capacity $\left(\mathrm{R}_{\mathrm{TOTAL}}\right)$ were fixed to the estimates from the binding analysis. Model equations are shown below and the model parameters are listed in Table 4.

$\mathrm{dD}_{\text {Central }} / \mathrm{dt}=\mathrm{k}_{\mathrm{pc}} \mathrm{D}_{\text {Peri }}+\mathrm{k}_{\text {off }} \mathrm{R}_{\text {Complex }}-\left(\mathrm{k}_{\mathrm{cp}}+\right.$

$\left.\mathrm{k}_{\text {on }} \mathrm{R}_{\text {Free }}+\mathrm{k}_{\text {Renal }}\right) \mathrm{D}_{\text {Central }}$

$\mathrm{dD}_{\text {Peri }} / \mathrm{dt}=\mathrm{k}_{\mathrm{cp}} \mathrm{D}_{\text {Central }}-\mathrm{k}_{\mathrm{pc}} \mathrm{D}_{\text {Peri }}$

$\mathrm{dR}_{\text {Complex }} / \mathrm{dt}=\mathrm{k}_{\text {on }} \mathrm{R}_{\text {Free }} \mathrm{D}_{\text {Central }}-\mathrm{k}_{\text {off }} \mathrm{R}_{\text {Complex }}$

$\mathrm{R}_{\text {Free }}=\mathrm{R}_{\text {Total }}-\mathrm{R}_{\text {Complex }}$

In these differential equations, $\mathrm{D}$ represents free drug (Gro $\beta$-T) concentration in blood, $\mathrm{R}$ represents DARC concentration in blood, $\mathrm{k}_{\mathrm{cp}}$ and $\mathrm{k}_{\mathrm{pc}}$ represent the intercompartmental distribution rate constants (central to peripheral and vice versa), and $\mathrm{k}_{\mathrm{on}}$ and $\mathrm{k}_{\text {off }}$ represent the chemokine-DARC association and dissociation rate constants (1 to 1 stoichiometry of binding).

Non-compartmental analysis was performed on the simulated profiles to estimate apparent CL, $\mathrm{V}_{\mathrm{ss}}$ and MRT using WinNonlin (Pharsight Corp., Version 4.1, Mountain View, CA). For steady-state simulations, mean, peak and trough steady-state plasma concentrations were estimated and their ratio calculated to estimate degree of fluctuation in the presence and absence of DARC. Finally, sensitivity analyses were performed to assess the impact of the arbitrary assignment of values for $\mathrm{k}_{\text {on }}$ and $\mathrm{k}_{\mathrm{cp}}$. The ratios of $k_{\text {on }}$ to $k_{\text {off }}$ and $k_{c p}$ to $k_{p c}$ were fixed by the equilibrium association constant and the desired ratio of compartment volumes ( $\mathrm{Vp} / \mathrm{Vc}$ of 2.5), respectively. CL, Vss and MRT were estimated for a range of values of $k_{c p}$ and $k_{o n}$ spanning several orders of magnitude to confirm general conclusions drawn from the base model.

Table 3. Distribution of $\left[{ }^{125} \mathrm{I}\right]$ Gro in Blood from African American Donors

\begin{tabular}{ccc} 
Donor & B/P & FY(A) Phenotype ${ }^{a}$ \\
\hline 1 & 0.543 & Negative \\
2 & 0.576 & Negative \\
3 & 0.608 & Negative \\
4 & 0.641 & Negative \\
5 & 0.697 & Negative \\
6 & 1.485 & Positive \\
7 & 1.663 & Positive \\
8 & 1.762 & Positive \\
Fraction & & $3 / 8$ (0.375) \\
FY(A)+ & & \\
\hline donors tested negative for Duffy antigen Fy(b).
\end{tabular}

Table 4. Pharmacokinetic Model Parameters used in the Simulation

\begin{tabular}{ccc} 
Parameter & Value & Units \\
\hline DARC $\mathrm{k}_{\text {on }}$ & 0.0870 & $\mathrm{nM}-1 \mathrm{~h}-1$ \\
DARC $\mathrm{k}_{\text {off }}$ & 2.0 & $\mathrm{~h}-1$ \\
$\mathrm{R}_{\mathrm{TOTAL}}$ & 38 & $\mathrm{nM}$ \\
$\mathrm{k}_{\mathrm{cp}}$ & 0.25 & $\mathrm{~h}-1$ \\
$\mathrm{k}_{\text {pc }}$ & 0.10 & $\mathrm{~h}-1$ \\
$\mathrm{k}_{\text {renal }}$ & 1.44 & $\mathrm{~h}-1$ \\
$\mathrm{~V}_{\text {central }}$ & 5200 & $\mathrm{~mL}$ \\
$\mathrm{~V}_{\text {peripheral }}$ & 13000 & $\mathrm{~mL}$ \\
DARC $_{\mathrm{D}}$ & 23 & $\mathrm{nM}$ \\
$\mathrm{V}_{\text {ss }}$ & 18200 & $\mathrm{~mL}$ \\
$\mathrm{CL}_{\text {renal }}$ & 7500 & $\mathrm{~mL} . \mathrm{h}-1$ \\
\hline & &
\end{tabular}

\section{RESULTS}

The distribution of radio-iodinated Gro $\beta$ - $T$ was studied in fresh whole blood from three Caucasian volunteers. At low concentrations ( $7 \mathrm{nM})$, on ice or following a 60 -min incubation at $37^{\circ} \mathrm{C}$, mean $\mathrm{B} / \mathrm{P}$ values of 1.7 to 1.8 were observed (Table 1 ). When cells were collected by centrifugation and washed, 
about $25 \%$ of the radioactivity was recovered in plasma and $34-50 \%$ of the radioactivity remained cell associated. Higher concentration of Gro $\beta-T$ (3300 nM) led to a substantial reduction in the blood to plasma concentration ratio, to values approaching one minus the hematocrit. This low $\mathrm{B} / \mathrm{P}$ of $\sim 0.6$, is the value expected for a drug that does not associate with blood cells. Consistent with this expectation, at the high ligand concentration, only about $2 \%$ of the radioactivity remained cellassociated following centrifugation and washing.

RANTES, a CC chemokine, was similarly effective in reducing the $\mathrm{B} / \mathrm{P}$ value when $7 \mathrm{nM}$ Gro $\beta$-T was incubated with $2500 \mathrm{nM}$ RANTES on ice (Table 1). These data suggest binding was specific to erythrocyte DARC as CC chemokines do not compete with CXC ligands for binding to the CXCR2 receptor on white blood cells and members of these chemokine families have been shown to interact competitively with DARC (7). Radioiodinated Groß-T remained stable under the conditions studied as there was no increase in the percentage trichloroacetic acid-soluble radioactivity over this concentration range, in the presence or absence of RANTES, and for up to $1 \mathrm{~h}$ at $37^{\circ} \mathrm{C}$.

To determine whether cell-bound radioactivity was associated with the cell surface or internalized, displacement studies were performed with excess unlabeled Gro $\beta-\mathrm{T}$. Following initial binding on ice or for $1 \mathrm{~h}$ at $37{ }^{\circ} \mathrm{C}$ using $7 \mathrm{nM}$ Gro $\beta$ $\mathrm{T}$, cells were washed, resuspended in buffer containing $3300 \mathrm{nM}$ unlabeled Gro $\beta-\mathrm{T}$, then incubated overnight at $4{ }^{\circ} \mathrm{C}$. Under these conditions, $70-80 \%$ of the radioactivity that initially bound could be dissociated from the cells (Table 2). Given that binding on ice was expected to inhibit internalization and only a modest difference in displacement was seen between incubation on ice and incubation at $37{ }^{\circ} \mathrm{C}$, Gro $\beta$-T appeared not be internalized by erythrocyte DARC. This is consistent with the results of studies of IL-8 (7) and suggests systemic clearance of Gro $\beta$ - $\mathrm{T}$ does not occur by way of erythrocyte DARC.

To characterize the interaction of Gro $\beta$-T with erythrocyte DARC quantitatively, Gro $\beta$-T was incubated with fresh whole blood from a single Caucasian donor over a broad concentration range (1-1000 nM) and the $\mathrm{B} / \mathrm{P}$ values and hematocrit were used to calculate the free and bound Gro $\beta$ - $T$ concentrations. The resulting binding isotherm is depicted in Figure 1 (top panel). The B/P versus total Gro $\beta$-T concentration data are also depicted in
Figure 1 (bottom panel). A single-site-binding model represented the data well. The apparent equilibrium dissociation constant $\left(\mathrm{K}_{\mathrm{D}}\right)$ was estimated to be $23.0 \pm 1.2 \mathrm{nM}$ while the capacity of binding $\left(\mathrm{R}_{\mathrm{TOTAL}}\right)$ was estimated to be $37.7 \pm 0.6$ $\mathrm{nM}$. These values are similar to those reported for IL-8 (a CXC chemokine) using purified erythrocytes (8).

A mutation in the DARC gene is common among African Americans and results in lack of expression of the erythrocyte antigen. The impact of the these differences in DARC expression on the distribution of Gro $\beta$-T was studied, in vitro, using fresh whole blood from eight African American volunteers. Antigen phenotyping was performed for each donor and the $\mathrm{B} / \mathrm{P}$ value was determined at 7 nM Gro $\beta-T$. The results are summarized in Table 3. A bi-modal distribution of $\mathrm{B} / \mathrm{P}$ values was observed. For five of the individuals, $\mathrm{B} / \mathrm{P}$ ranged from 0.5-0.7, and the corresponding FY(A) phenotypes were negative. For the other three individuals, $\mathrm{B} / \mathrm{P}$ ranged from 1.5-1.8 and the corresponding $\mathrm{FY}(\mathrm{A})$ phenotypes in these individuals were positive. In the $\mathrm{FY}(\mathrm{A})$ positive individuals, the $\mathrm{B} / \mathrm{P}$ value at $7 \mathrm{nM}$ was within the range observed in Caucasian volunteers. The $\mathrm{B} / \mathrm{P}$ value was highly correlated with the presence or absence of the Duffy antigen ( $p<0.01$, t-test) and the proportion of African Americans for which binding of Gro $\beta$-T was observed (3 of 8), was consistent with the reported frequency of DARC expression in this population (15).

\section{DISCUSSION}

Duffy was originally characterized as a major blood group antigen and as the receptor for the malaria parasite, Plasmodium vivax $(9,16)$. Subsequently, the Duffy antigen was shown to be identical to the red blood cell chemokine receptor (8) and was designated the Duffy Antigen/Receptor for Chemokines (DARC). DARC is a promiscuous receptor that binds many CC and CXC chemokines. Though a seven transmembrane protein, DARC is not involved in chemokine signal transduction (7). Thus Duffy antigen has been postulated to act as a regulatory protein that binds and inactivates excess circulating chemokine (8).

The Duffy antigen is subject to genetic polymorphism in humans. A majority of Caucasians are positive for either one or both of the codominant alleles $\mathrm{FY}^{*} \mathrm{~A}$ and $\mathrm{FY} * \mathrm{~B}$ conferring 
positive Duffy antigen phenotypes $\mathrm{Fy}(\mathrm{a}+\mathrm{b}+)$, Fy(a+b-) and Fy(a-b+). The homozygous negative phenotype in which DARC is not expressed (Fy(ab-)) is very rare in the Caucasian population. However, in African Americans, the negative Duffy phenotype is very common, as nearly two-thirds of these individuals do not express DARC (15). The higher frequency of the negative phenotype in Africa (approaching 100\%) suggests the causative gene mutation protects individuals from malaria infection and confers a survival benefit (9).

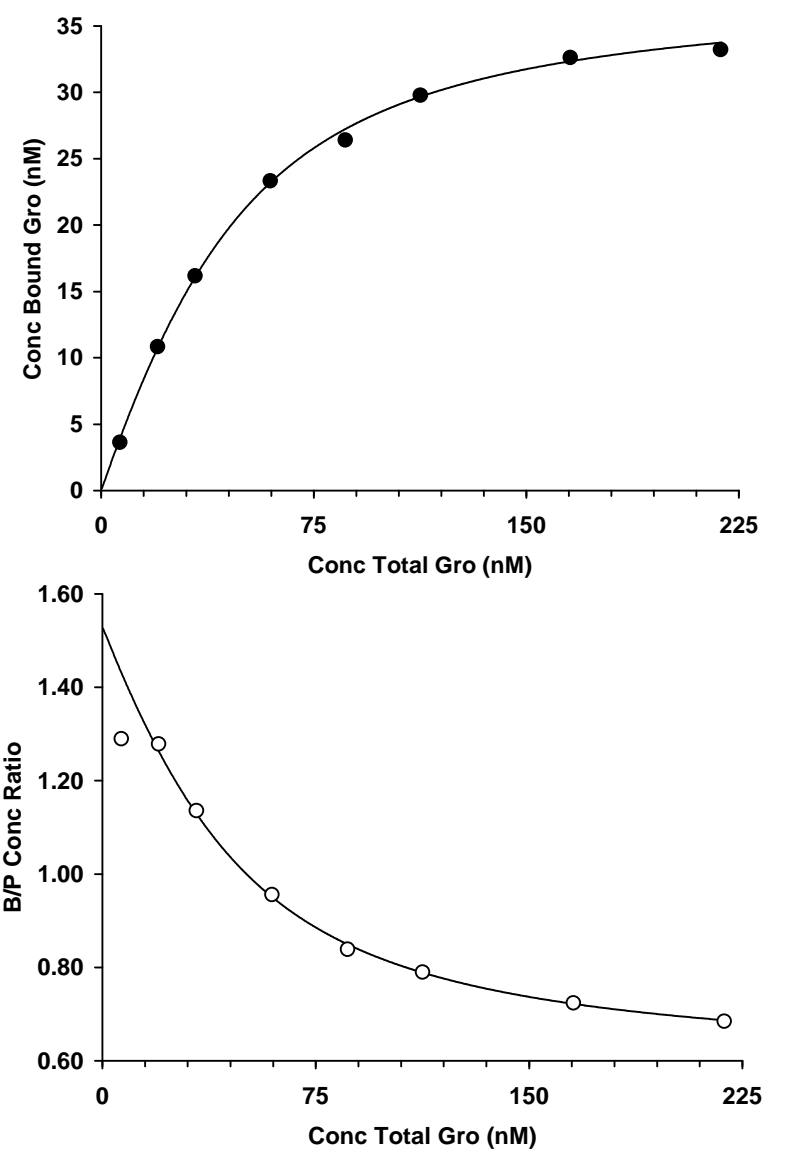

Figure 1. Binding isotherm for the interaction of Gro $\beta-T$ with the Duffy Antigen Receptor for Chemokines on human erythrocytes (top panel). Radiolabeled Groß-T was added to ice-cold whole blood from a single healthy Caucasian volunteer. Plasma was collected by centrifugation and concentrations of drug in whole blood and plasma were determined by scintillation counting. Free and bound Gro concentrations were calculated as described in the text. The apparent $\mathrm{K}_{\mathrm{D}}$ and $\mathrm{R}_{\text {TOTAL }}$ were estimated to be 23 and $38 \mathrm{nM}$, respectively. Model predicted values are shown as a solid line. The corresponding blood to plasma ratio versus total Gro concentration is also shown (bottom panel).
In the present study, the interaction of Gro $\beta$-T with erythrocyte DARC has been characterized. In addition, the impact of differential expression of erythrocyte DARC on the distribution of the chemokine in whole blood was investigated. The absence of DARC leads to a relatively higher concentration of free chemokine in vitro. This is particularly evident at lower total chemokine concentrations and is consistent with the hypothesis that DARC is a chemokine sink. The potential impact of differential DARC expression on the in vivo disposition of a chemokine administered therapeutically is perhaps less clear. In an effort to enhance our understanding of the potential consequences of chemokine-DARC interaction in vivo, in the absence of human data, we have simulated the plasma concentration-time profile of Gro $\beta$-T following iv administration to humans (Figure 2). The pharmacokinetic model makes reasonable assumptions about the behavior of the chemokine and explicitly accounts for saturable, reversible binding to erythrocyte DARC.

For many low molecular weight proteins, glomerular filtration is the primary elimination mechanism and total body clearance values approximate the glomerular filtration rate (17). Binding to pharmacologic receptor, with subsequent internalization and catabolism, may also be an important determinant of the pharmacokinetics of a protein therapeutic $(18,19)$. Internalization and catabolism may lead to pharmacokinetic nonlinearity, particularly at low doses, as we have described for the mouse (10). Due to the additional model complexity this would introduce, and our desire to minimize the arbitrary assignment of parameter values, we have not accounted for this potential mechanism of clearance.

Steady-state distribution volumes for protein therapeutics commonly vary between plasma volume and extracellular water as these molecules are inherently hydrophilic and are not able to cross cell membranes. Apparent distribution volume in humans might be affected by the binding of Gro $\beta$-T to heparin sulfate proteoglycans in the extracellular matrix as has been demonstrated for hepatocyte growth factor and interleukin-8 $(20,21)$. Again due to the complexity this would introduce, we have not explicitly accounted for the binding of GroB to proteoglycan in our simulations. Nonetheless, the simple model employed allows us to consider, in isolation, the potential impact of DARC on the disposition of Gro $\beta$-T in humans. 

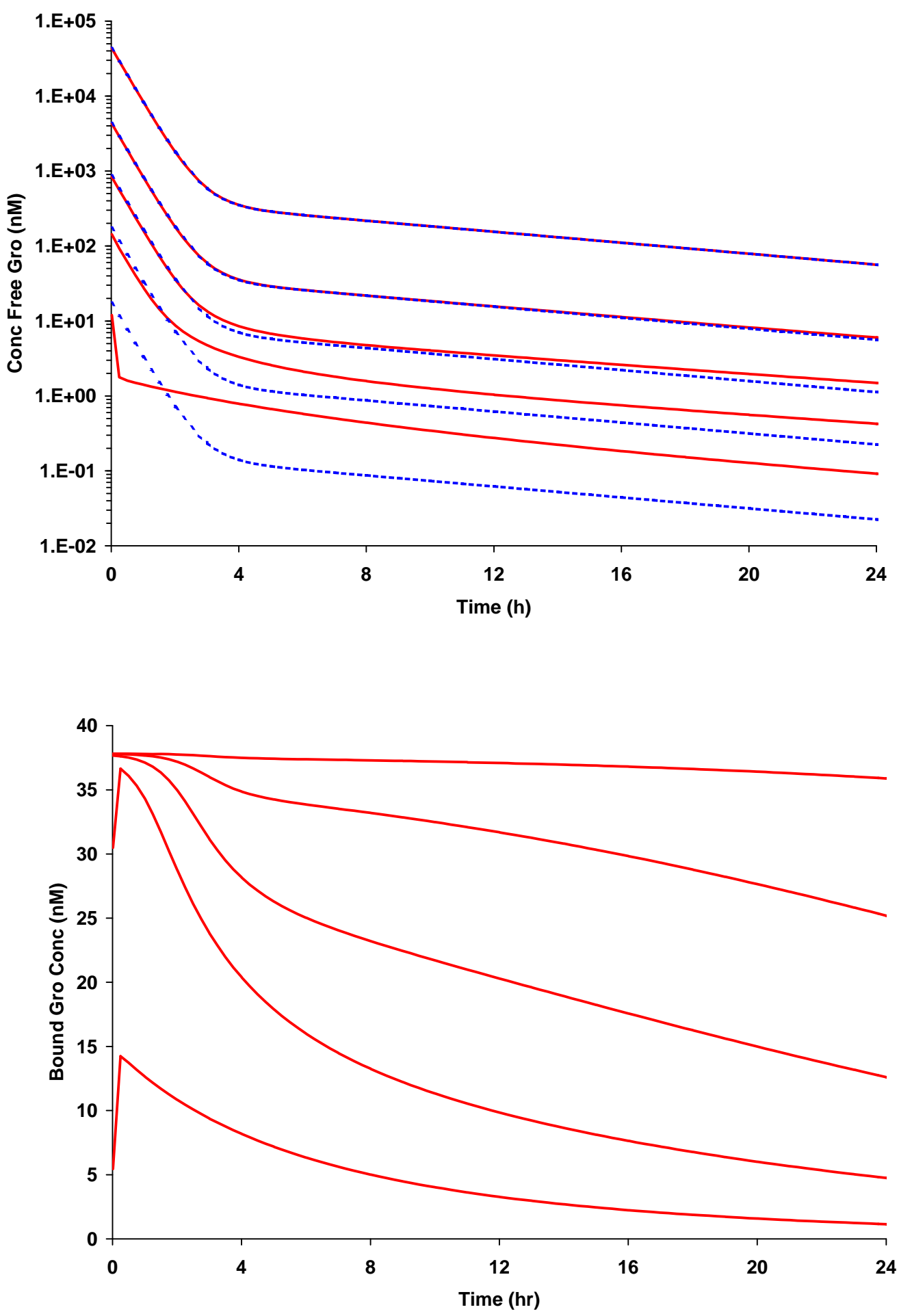

Figure 2. Impact of DARC expression on the intravenous pharmacokinetics of Gro $\beta$ - $T$ in humans. The top panel depicts the model-predicted concentration of free (unbound) Gro $\beta$-T in blood in the absence (dotted lines) and presence (solid lines) of DARC. Single iv bolus doses are $0.01,0.1,0.5,2.5$ and $25 \mathrm{mg} / \mathrm{kg}$. The bottom panel depicts the model-predicted concentration of Gro $\beta$-T bound to DARC on the erythrocyte cell surface in whole blood for the same 5 dose levels (in the presence of DARC). Red curves are the profiles predicted for individuals expressing the Duffy antigen. Dose proportional increases in free concentration of Gro $\beta$-T are observed in the absence of DARC while non-linear pharmacokinetics are apparent, particularly at low doses in the presence of DARC, due to saturable binding to the erythrocyte antigen. 
At the highest dose simulated (25 mg/kg), when chemokine concentration greatly exceeds the total DARC concentration, there is no notable difference between the concentration-time profile, of free Gro $\beta$-T, in the presence and absence of DARC (Figure 2, top panel). Also, under these conditions, the concentration of Gro $\beta$-T bound to DARC remains virtually constant over $24 \mathrm{~h}$, at a value near the concentration of total DARC in blood (38 nM, Figure 2, bottom panel). This follows from the fact that the concentrations of free Gro $\beta-T$ at this high dose exceed total DARC by two orders of magnitude initially and are still in substantial excess of total DARC $24 \mathrm{~h}$ after administration $(\sim 100 \mathrm{nM})$.

At the lowest dose $(0.01 \mathrm{mg} / \mathrm{kg})$, the initial concentration $\left(\mathrm{C}_{\max }\right)$ is higher in the absence of DARC ( 45\%) consistent with our expectation based on the in vitro data. In the presence of DARC, the initially lower concentrations decline relatively rapidly reflecting rapid association with the erythrocyte receptor (Figure 2, top panel). Thus, free Gro $\beta$ - $\mathrm{T}$ concentrations are higher in the absence of DARC for $\sim 2 \mathrm{~h}$ after dosing during which time concentrations decline approximately 10 -fold in both situations. The concentration range spanned during this time frame $(1-10 \mathrm{nM})$ is on the order of the $K_{D}$ for interaction of Gro $\beta$-T with its pharmacologic receptor, CXCR2. The magnitude of the difference in the 2 profiles ( \pm DARC) over this time frame is affected both by the association rate constant $\left(\mathrm{k}_{\mathrm{on}}\right)$ and the rate of drug elimination $\left(\mathrm{k}_{\text {renal }}\right)$; changes in either of these have the potential to impact the magnitude of the difference. Nonetheless, transiently higher free Gro $\beta-T$ concentrations, in the absence of DARC, may be of some pharmacologic significance particularly given the potential for rapid equilibration of free Gro $\beta-T$ with its pharmacodynamic effect compartment.

In the terminal disposition phase, concentrations of free Gro $\beta$ - $T$ in the presence of DARC can be substantially higher than in the absence of DARC. Insight on this phenomenon, given the complex dynamics of the in vivo situation, cannot be readily gained from in vitro studies of chemokine-DARC interaction. At $0.01 \mathrm{mg} / \mathrm{kg}, 4 \mathrm{~h}$ after dosing, the free Gro $\beta$-T concentration is $\sim 0.8$ $\mathrm{nM}$ in the presence of DARC and $<0.2 \mathrm{nM}$ in the absence of DARC. The absolute concentrations (presence or absence of DARC) are perhaps relatively low at this time-point but the rate of further decline in concentration during these apparent terminal disposition phases is much slower than in the initial disposition phases. Therefore, these concentrations persist for some time and the concentration of free Gro $\beta$-T would be expected to be higher in individuals expressing DARC than in those that do not for a substantial period of time.

Non-compartmental analysis of the simulated data confirm that the apparent blood CL of free Gro $\beta$-T is largely unaffected by the presence of DARC ( $<6 \%$ difference at a dose of $0.01 \mathrm{mg} / \mathrm{kg}$ ). Consistent with this, in a simulation of multiple dosing of $0.01 \mathrm{mg} / \mathrm{kg}$ 3-times daily, at steady state, the average concentration of free chemokine was the same in the presence or absence of DARC $(<6 \%$ difference). The apparent Vss and MRT, however, were higher in the presence of DARC (at the lowest dose depicted, 3.5-fold) and this increased the degree of fluctuation at steady state from 20 to 100fold for this particular multiple dose regimen. In the simulations, lower doses consistently resulted in increased apparent volume for a range of values of $\mathrm{k}_{\mathrm{cp}}$ and $\mathrm{k}_{\mathrm{on}}$. As the dose is increased, the volume in the presence of DARC approaches the volume in the absence of DARC. One notable exception was that for extremely low values of $k_{\mathrm{cp}}$ the impact of the peripheral compartment on the steady-state distribution volume is negligible with or without DARC at higher doses and $V_{s s}$ falls below the values in the base model.

The question we have asked in this report regarding the potential impact of differences in erythrocyte DARC expression on the pharmacokinetics of a chemokine in humans is similar to a more general question that has received considerable attention. Namely, what are the expected clinical consequences of increased free fraction of a drug arising from protein binding drugdrug interaction (22)? Many of the conclusions drawn from consideration of this analogous issue are consistent with those drawn here. Though the model employed in this study is likely to be overly simplistic, the modeling and simulation exercise provide a means of optimizing the design of future pharmacokinetic and pharmacodynamic studies and of testing specific hypotheses. A thorough understanding of the impact of erythrocyte DARC on the PK/PD of Gro $\beta$-T will ultimately be realized from detailed investigations of Gro $\beta$-T in humans. 


\section{ACKNOWLEDGMENTS}

We thank Robert C Gagnon for statistical analyses and Robert A Copeland for critical review of the manuscript.

\section{REFERENCES}

[1]. Rollins, B. J. Chemokines. Blood, 90: 909, 1997.

[2]. Baggiolini, M. Chemokines and leukocyte traffic. Nature, 392: 565-568, 1998.

[3]. Schwarz, M. K. and Wells, T. N. C. Recent developments in modulating chemokine networks. Exp. Opin. Ther. Patents, 9: 14711490, 1999.

[4]. King, A. G., Johanson, K., Fry, C. L., Demarsh, D. L., White, J. R., McDevitt, P., McNulty, D., Balcarek, J., Jonak, Z. L., Bhatnager, P. K. and Pelus, L. M. Identification of unique truncated $\mathrm{KC} / \mathrm{GRO} \beta$ chemokines with potent hematopoietic and anti-infective activities. $J$ Immunol, 164: 3774-3782, 2000.

[5]. King, A. G., Horowitz, D., Dillon, S. B., Levin, R., Farese, A., MacVittie, T., Pelus, L. Rapid mobilization of murine hematopoietic stem cells with enhanced engraftment properties and evaluation of hematopoietic progenitor cell mobilization in rhesus monkeys by a single injection of SB-251353, a specific truncated form of the human CXC chemokine GRO $\beta$. Blood, 97: 1534-1542, 2001.

[6]. Chaudhuri, A., Polyakova, J., Zbrzezna, V., Williams, K., Gulati, S., Pogo, A.O. Cloning of glycoprotein D cDNA, which encodes the major subunit of the duffy blood group system and the receptor for the Plasmodium vivax malaria parasite. Proc. Natl. Acad. Sci. USA 90: 1079310797, 1993.

[7]. Neote, K., Mak, J. Y., Kolakowski, L. F. Jr., Schall, T. J. Functional and biochemical analysis of the cloned Duffy antigen: identity with the red blood cell chemokine receptor. Blood, 84: 44-52, 1994.

[8]. Darbonne, W. C., Rice, G. C., Mohler, M. A., Apple, T., Hebert, C. A., Valente, A. J., Baker, J. B. Red blood cells are a sink for interleukin 8, a leukocyte chemotaxin. J. Clin. Invest., 88: 13621369, 1991.

[9]. Miller, L. J., Mason, S. J., Clyde, D. F., McGinniss, M. H. (1976) The resistance factor to Plasmodium vivax in blacks. The Duffy-bloodgroup phenotype, FyFy. New Engl. J. Med., 295: 302-304, 1976.

[10]. Hepburn, T. W., Hart, T. K., Horton, V. L., Sellers, T. S., Tobia, L. P., Urbanski, J. J., Shi, W., Davis, C. B. Pharmacokinetics and tissue distribution of SB-251353, a novel human CXC chemokine, after intravenous administration to mice. J. Pharmacol. Exp. Ther., 298: 886-893, 2001.

[11]. Davis, C. B., Boyle, K. E., Urbanski, J. J., Paradysz, R. T., Fong, K.-L. L. Disposition of metabolically labeled recombinant soluble CD4 (sT4) in male Sprague-Dawley rats following intravenous and subcutaneous administration. Drug Metab. Dispos., 20: 695-705, 1992.

[12]. Gloff, C. and Wills, R., Pharmacokinetics and metabolism of therapeutic cyto-kines, in Ferraiolo, B., Mohler, M., Gloff, C., (eds), Protein Pharmacokinetics and Metabolism, Plenum Press, New York, NY, pp 127-150, 1992.

[13]. Davies, B. and Morris, T. Physiological parameters in laboratory animals and humans. Pharm. Res., 10: 1093-1095, 1993.

[14]. Mager, D. E., Neuteboom, B., Efthymiopoulos, C., Munafo, A., Jusko, W. J. Receptor-Mediated Pharmacokinetics and Pharmacodynamics of Interferon- $\beta 1$ a in Monkeys. J. Pharmacol. Exp. Ther., 306: 262-270, 2003.

[15]. Sanger, R., Race, R. R., Jack, K. A. The Duffy blood groups of New York Negroes: The phenotype Fya-b-. Br. J. Heaematol. 163: 253258, 1955.

[16]. Barnwell, J. W., Nichols, M. E., Rubinstein, P. In vitro evaluation of the role of the duffy blood group in erythrocyte invasion by Plasmodium vivax. J. Exp. Med.., 169: 1795-1802, 1989.

[17]. Maack, T., Johnson, V., Kau, S. T., Figueredo, J. and Sigulem, D. Renal filtration, transport and metabolism of low-molecular-weight proteins: a review. Kidney Int. 16: 251-270, 1979.

[18]. Hepburn, T.W., Davis, C.B., Urbanski, J.J. Smith, B.R., Schaefer, W.H., Carbonaro, M.A. and Bugelski, P.J. Renal Catabolism of Recombinant Human Soluble CD4 Following Intravenous Administration to Male SpragueDawley Rats. Drug Metab. Dispos., 23: 10441050, 1995.

[19]. Kuwabara, T., Uchimura, K., Takai, H., Kobayashi, H., Kobayashi, S. and Sugiyama, Y. Saturable uptake of a recombinant human granulocyte colony-stimulating factor derivative, nartograstim, by the bone marrow and spleen of rats in vivo. J. Pharmacol. Exp. Ther. 273: 11141122, 1995.

[20]. Liu, K.-X., Kato, Y., Terasaki, T., Aoki, S., Okumura, K., Nakamura, T. and Sugiyama Y. Contribution of parenchymal and nonparenchymal liver cells to the clearance of hepatocyte growth factor from the circulation of rats. Pharm Res 12: 1737-1740, 1995.

[21]. Kuschert, G.S.V., Hoogewerf, A.J., Proudfoot, A.E.I., Chung, C.W., Cooke, R.M., Hubbard, R.E. and Wells, T.N.C. Identification of a 
glycosaminoglycan binding surface on human interleukin-8. Biochemistry 37: 11193-11201, 1998.

[22]. Benet, L. Z. and Hoener, B. Changes in plasma protein binding have little clinical relevance. Clin. Pharmacol. Ther., 71: 115-121, 2002. 